\title{
The impact of parental catastrophizing and contextual threat on parents' emotional and behavioral responses to their child's pain
}

Caes, L. ${ }^{1}$, MSc, Vervoort, T. ${ }^{1}, \mathrm{PhD}$, Trost, Z., $\mathrm{PhD}^{2}$, Goubert, L. ${ }^{1}, \mathrm{PhD}$

1 Department of Experimental-Clinical and Health Psychology, Ghent University, Belgium

2 Department of Psychology, McGill University, Montréal, Canada

* Corresponding author: Line Caes, Department of Experimental-Clinical and Health Psychology, Ghent University, Henri Dunantlaan 2, B- 9000 Ghent, Belgium. Tel: +32 (0)9 2648612 Fax: +32 (0)9 26464 71. Electronic mail may be sent to Line.Caes@,Ugent.be

Line Caes is an Aspirant fellow of the Fund for Scientific Research - Flanders (Belgium) (F.W.O.) and is a trainee member of Pain in Child Health, a strategic research training initiative of the Canadian Institutes of Health Research.

Tine Vervoort is a Post-doctoral fellow of the Fund for Scientific Research - Flanders (Belgium) (F.W.O.).

\section{Category: Original article}

Number of text pages: 33

Number of tables: 1

Number of Figures: 4

Keywords: parents, pain catastrophizing, distress, fear-potentiated startle reflex, corrugator

EMG activity, parental behavior 


\section{ABSTRACT}

Limited research has addressed processes underlying parents' empathic responses to their child's pain. The present study investigated the effects of parental catastrophizing, threatening information about the child's pain, and child pain expression upon parental emotional and behavioral responses to their child's pain. Fifty-six schoolchildren participated in a heat pain task consisting of 48 trials while being observed by one of their parents. Trials were preceded by a blue or yellow circle, signaling possible pain stimulation (i.e., pain signal) or no pain stimulation (i.e., safety signal). Parents received either neutral or threatening information regarding the heat stimulus. Parents' negative emotional responses when anticipating their child's pain were assessed using psychophysiological measures -- i.e., fearpotentiated startle and corrugator EMG activity. Parental behavioral response to their child's pain (i.e., pain attending talk) was assessed during a 3-minute parent-child interaction that followed the pain task. The Child Facial Coding System (CFCS) was used to assess children's' facial pain expression during the pain task. Results indicated that receiving threatening information was associated with a stronger parental corrugator EMG activity during pain signals in comparison with safety signals. The same pattern was found for parental fear-potentiated startle reflex, particularly when the child's facial pain expression was high. In addition, parents who reported high levels of catastrophizing thought about their child's pain engaged, in comparison with low catastrophizing parents, in more pain-attending talk when they received threatening information. The findings are discussed in the context of affective-motivational theories of pain. 


\section{INTRODUCTION}

Pain is a common complaint in children [66] and parental factors are known to play a central role in the child's pain experience $[13,42]$. Specifically, parental responses may have adaptive as well as maladaptive influences upon their child's pain $[13,16,48,63,79,80,81]$. For example, in response to pain, parental "pain-attending" behaviors, such as reassuring, giving attention to child pain and limiting the child's activities, are generally related to more disability in the child $[27,56,64,68]$. To date, it is still largely unknown why and when parents engage in particular patterns of behavior in response to child pain $[49,64]$.

Research has suggested that parental pain catastrophizing (i.e., misinterpreting and exaggerating the threat value of their child's pain) and associated emotional distress may impact parental behavior in response to child pain $[11,68]$. Specifically, high catastrophizing parents are more likely to experience elevated distress when faced with their child in pain $[11,36,39]$ and are more inclined to engage in pain-attending behaviors [11,68]. However, research on how heightened parental catastrophizing translates into parental distress and specific behavior towards child pain is currently limited to self-report studies, which may not be a valid index of actual parental responses [18]. Therefore, the current study sought to investigate the influence of parental catastrophizing upon psychophysiological indices of parental distress and observed parental pain-attending behavior.

However, not all pain situations children encounter are alike. There is reason to believe that, in addition to parental characteristics (e.g., catastrophizing), contextual variables such as additional information concerning the situation $[55,75]$ and child characteristics, such as facial pain expression $[42,82]$ may be important in explaining variations in parental responses to child pain. These variables may augment the threat value parents assign to the child's pain experience (i.e., contextual threat), thereby enhancing parental distress and possibly pain-attending responses $[5,6,20,67,70,82]$. Accordingly, the present study additionally examined whether contextual information or child pain expression interacts with 
parental catastrophizing to impact parental emotional and behavioral responses to their child's pain.

Parents observed their children undergo a heat pain task, which was followed by a 3minute interaction between parent and child. Prior to observing their child in pain, parents received either neutral or threatening information about the pain stimulus. The fearpotentiated startle reflex $[23,40,43,51,52]$ and EMG activity over the corrugator muscle $[25,26]$ served as psychophysiological indices of parental distress while anticipating pain in their child. Both indices have been shown to reflect an aversive emotional response to negative events, such as pain, happening to the self as well as to others $[8,9,25,26,41,43,53,65,73]$. Subsequently, parental behavioral response to their child's pain was assessed during the parent-child interaction period. Specifically, we measured parental pain-attending talk as an index of parental pain-attending behavior [81]. We expected that higher levels of parental catastrophizing, threatening information, and child pain expression would be associated with elevated levels of parental distress and pain-controlling behavior (i.e., pain-attending talk). In addition, we expected the influence of parental catastrophizing to be enhanced when contextual threat was high due to threatening information and/or child pain expression.

\section{METHODS}

\subsection{Participants}

Participants were recruited from a sample of school children $(N=403)$ from grades 6 through 9 and their parents who had participated approximately two years earlier in a questionnaire study. Only children and parents who had given consent to be re-contacted and who were not invited to participate in another study were approached $(N=280)$. Children and their parents were eligible to participate if the child did not suffer from chronic illness, including recurrent or chronic pain, or a developmental disorder. The child and parent were 
required to speak and write Dutch. A weighted random sampling procedure was used [45] to ensure an equal proportion of boys and girls and equal age distribution. Of the 280 parentchild dyads that had consented to be re-contacted, 133 dyads were randomly selected and contacted. Of those contacted, $1.50 \%(N=2)$ met the exclusion criteria and $58.02 \%(N=76)$, of the remaining 131 dyads, agreed to participate. Ten parent-child dyads later withdrew their consent to participate because of child illness or family responsibilities. In addition, one child withdrew participation before the pain task concluded and two parent-child dyads could not take part due to failure of the pain induction equipment. This resulted in a final sample of 63 parent-child dyads (32 boys, 31 girls and 49 mothers, 14 fathers) who participated in the entire experimental protocol.

Children ranged in age from 11 to 15 years $(M=13.08$ years; $S D=1.34)$. Parents ranged in age from 34 to 55 years $(M=44.25$ years, $S D=4.71)$. Most parents $(61.9 \%)$ were married or co-habiting. The majority of the parents $(73 \%)$ had had education beyond the age of 18 years. All participating children and parents were Caucasian. Participants were compensated $35 €$ for participating in this study. The study was approved by the Ethics Committee of the Faculty of Psychology and Educational Sciences of Ghent University, Belgium. The sample described below has been examined in two prior studies addressing parental detection and attentional processing of child pain $[76,77]$.

\subsection{Pain task}

Children participated in a heat pain task consisting of 48 trials while being observed by one of their parents from an adjacent room. Parents could observe their child by means of a television screen displaying their child's face. Each trial of the pain task was preceded by presentation of either a yellow or blue circle. One colour signaled a possible pain trial ("pain signal") indicating to parents that a heat stimulus at tolerance level could potentially be delivered to the child following appearance of the coloured circle. The other colour signaled a 
non-pain trial ("safety signal") indicating that no heat stimulus would follow. Whether a yellow or blue circle signaled pain or safety was counterbalanced across participants. Prior to the pain task, parent and child were informed which colour (i.e., blue or yellow) represented a pain or safety signal. These coloured circles were synchronically presented to the child and their parent on respective computer screens by means of Inquisit (Millisecond Software [47]). The pain task consisted of 48 trials in total, preceded by 24 pain signals and 24 safety signals (see Fig. 1 for an overview of an individual trial). Each trial started with a fixation cross, displayed in the centre of the computer screen for $1 \mathrm{~s}$, followed by the presentation of a pain or safety signal (i.e., blue or yellow circle) for 8 s. After the presentation of the pain/safety signal, a white screen appeared for $7-9 \mathrm{~s}$. On presentation of the white screen, the child received a painful heat stimulus following $25 \%(N=6)$ of the pain signals. No pain stimulation followed any of the 24 safety signals. At the end of each trial, the computer screen turned beige for $10 \mathrm{~s}$.

Insert Fig 1 about here

\subsection{Heat stimuli}

The Contact Heat Evoked Potentials Stimulator (CHEPS) of the Medoc Neuro Sensory Analyzer, Model TSA-II (Medoc Ltd. Advanced Medical Systems, Ramat, Yishai, Israel) with a thermode contact area of $572.5 \mathrm{~mm}^{2}$ was used for heat stimulation. The entire thermode-stimulating surface was placed in contact with the skin testing side and secured by a Velcro strap. Heat stimuli were delivered with an accelerated velocity of $50^{\circ} \mathrm{C} / \mathrm{s}$ and a cooling rate of $40^{\circ} \mathrm{C} / \mathrm{s}$. Thermal stimuli were delivered at tolerance level to the inside of the right wrist for $1500 \mathrm{~ms}$. Pain tolerance level was individually determined before the start of the pain task by increasing the temperature of the heat stimuli in an ascending sequence until children's tolerance level. Specifically, starting with baseline temperature of $32^{\circ} \mathrm{C}$, temperature was increased by $1{ }^{\circ} \mathrm{C}$ for $1500 \mathrm{~ms}$ and returned to baseline upon stimulus 
termination. Children then indicated if they wanted to stop at this temperature or to increase the temperature further by $1{ }^{\circ} \mathrm{C}$. For safety purposes, the Medoc software limited the maximum temperature of the $1500 \mathrm{~ms}$ heat stimuli to $50^{\circ} \mathrm{C}$. Upon reaching their tolerance level, children were asked to rate how painful this heat stimulus was on a numerical rating scale (NRS) ranging from 0 ('no pain') to 10 ('a lot of pain'). This specific heat pain task is an ethically approved and safe pain task that has been used in previous studies in comparable age groups [see e.g., 44, 84].

\subsection{Threat manipulation}

Parents were randomly assigned to either a group receiving neutral information or a group receiving threatening information. Parents receiving neutral information regarding the heat stimulus their child could experience following a pain signal were provided with the following information: "During this task, your child will receive several heat stimuli of different intensities. Our experience with the heat stimuli used in this study indicates that children might experience some of the heat stimuli as slightly unpleasant. Therefore, it is possible that some of the heat stimuli are also slightly unpleasant for your child". In parents who received threatening information, the threat value of the heat stimulus was enhanced by providing the parents with threatening information about the pain experience of their child ("During this task, your child will receive several heat stimuli of different intensities, with some of them being possibly painful. Our experience with the heat stimulus used in this study indicates that children might experience some of the heat stimuli as painful and have difficulty dealing with them. Therefore, it is possible that some of the heat stimuli may also be painful and barely tolerable for your child"). In addition to the above information, parents were shown photographs as visual examples of how children generally cope with the heat stimuli. These photographs were selected from video material of previous child pain studies. Parents receiving neutral information were shown photographs of children displaying low 
pain expression. Parents receiving threatening information were shown images of children expressing high pain. For purposes of standardization, the neutral/threatening information and photographs were presented using Office PowerPoint.

To assess the effectiveness of the threat manipulation, we measured parents' state catastrophic thought about their child's heat pain both prior to and following the child pain task. For this purpose, a state measure of the original Pain Catastrophizing Scale for Parents was used [PCS-P; 36, see below]. In line with previous studies [11,37], the PCS-P-state comprised one adapted item from each PCS-P subscale (Rumination: "At this moment, to what extent do you keep thinking/did you keep thinking about how painful the heat stimuli are/were for your child?"; Magnification: "At this moment, to what extent do/did you keep thinking something serious might happen to your child during administration of the heat stimuli?"; Helplessness: "At this moment, to what extent do/did you think you would not be able to endure the administration of the heat stimuli?"). Parents rated the three items on an 11-point NRS with the endpoints 0 (not at all) and 10 (a lot). A mean score of these three items was calculated ranging from 0 to 10 . The Cronbach's $\alpha$ 's for the PCS-P-state measure were .62 and .53 , respectively, for PCS-P-state before and the PCS-P-state after the pain task.

\subsection{Psychophysiological recordings}

We used the fear-potentiated startle reflex and EMG activity over the corrugator muscle as indicators of parental negative emotional response in anticipation of pain in their child (i.e., during pain and safety signals) [25,43]. Although heightened levels of both measures suggest the activation of a self-oriented, aversive system [25,26,51,52] they seem to reflect different aspects of the negative emotional response. Specifically, the fear-potentiated startle is a sympathetic reflex indicating the activation of a defensive-motivational circuit, while the corrugator EMG activity assesses the facial muscle activity associated with processing negative events $[8,25,40]$. 
The fear-potentiated startle reflex was measured as the magnitude of the eye blink modulation to a sudden probe. Three $\mathrm{Ag} / \mathrm{AgCl}$ electrodes with a diameter of $0.4 \mathrm{~cm}$ were filled with highly conductive gel and placed over the orbicularis occuli muscle of the left eye. After cleaning the skin with alcohol, one electrode was placed just below the left pupil, the second was placed $1 \mathrm{~cm}$ laterally. The ground electrode was placed on the forehead [see 7]. The acoustic startle probe was a $50 \mathrm{~ms}$ burst of white noise (90-100 dB) with instantaneous rise time, presented binaurally over headphones. To prevent parental habituation to the startle probe, startle probes were administered at different time points during the pain and safety signals (i.e., at $3 \mathrm{~s}$ or at $6 \mathrm{~s}$ after pain/safety signal onset).

The EMG response over the corrugator muscle was registered with two $\mathrm{Ag} / \mathrm{AgCl}$ electrodes with a diameter of $.40 \mathrm{~cm}$, filled with conductive gel. After cleaning the skin with alcohol, these electrodes were placed at the corrugator muscle above the left eye. The same forehead ground electrode as for the startle reflex was used [see, 32]. For both psychophysiological measures, an EMG100C Electromyogram Amplifier was used to record the raw electromyographic (EMG) signals with the high pass filter set at $90 \mathrm{~Hz}$, and the low pass filter at $500 \mathrm{~Hz}$. All psychophysiological responses were sampled at $1000 \mathrm{~Hz}$. In line with guidelines specified by Blumenthal and colleagues [7], the psychophysiological data were integrated and analyzed off-line using Psychophysiological Analysis (PSPHA; [24]).

\subsection{Child facial pain expression}

Children's facial pain expression during the pain task was video recorded and coded by means of the Child Facial Coding System [CFCS; 10,14,33]. The CFCS is an observational rating system of 13 discrete facial actions (brow lowering, squint, eye squeeze, nose wrinkle, nasolabial furrow, cheek raiser, upper lip raise, lip corner pull, vertical mouth stretch, horizontal mouth stretch, blink, flared nostril and open lips). The facial actions blink, flared nostril, open lips are coded for presence only ( 0 or 1$)$ while the remaining 10 facial 
expressions are coded for both presence and intensity $(0=$ no action, $1=$ slight action, $2=$ distinct/maximal action). Child facial pain expression was coded for the six trials in which a pain stimulus followed the presentation of a pain signal. Specifically, the facial pain expression was coded during the 20 -second time interval preceding presentation of the beige screen. Each second of the 20 -second interval was coded using a software program enabling the rater to view and review each second at normal rate and at a rate of $1 / 10$ of a second. For each time interval, a mean score per second for each of the 13 facial actions was calculated. A total score ranging between 0 and 138 was calculated by summing these mean scores. One trained coder rated the facial expressions for all participants. A second trained coder independently coded a random sample $(20 \%)$ of the videotapes in order to determine the inter-rater reliability according to the formula provided by Ekman \& Friesen [31]. The interrater reliabilities were acceptable for overall frequency $(.80$; range $=.70-.93)$ and for overall intensity $(.77$; range $=.67-.93)$ of child pain expression.

\subsection{Parental catastrophizing about their child's pain}

Parental catastrophic thinking about their child's pain was assessed with the Dutch version of the Pain Catastrophizing Scale for Parents [PCS-P; 36]. This instrument is an adaptation of the adult Pain Catastrophizing Scale [PCS; 69] and the Pain Catastrophizing Scale for Children [PCS-C; 19]. The PCS-P consists of 13 items describing different thoughts and feelings that parents may experience when their child is in pain. Parents rate how frequently they experience each of the thoughts and feelings when their child is in pain using a 5-point scale $(0=$ 'not at all', $4=$ 'extremely'). The PCS-P yields a total score that can range from 0 to 52, and three subscale scores for rumination, magnification and helplessness. The PCS-P has been shown to be reliable and valid [36]. The Cronbach's alpha in this study was $\alpha=.89$.

\subsection{Parent-child interaction}


Following the pain task, parents and children were reunited and left alone for three minutes in order to videotape their interaction. A transcript of the utterances of parent and child during this interaction was made. The coding system used in the present study was based upon the coding procedure developed by Walker et al. (2006) [81]. Accordingly, mutually exclusive codes were assigned to parental utterances: (1) Pain attending talk, defined as any talk by the parent that focuses upon the child's pain experience (e.g., 'Did it hurt a lot?'; 'Are you still in pain now?'), (2) Non-pain attending talk, defined as parent utterances that did not focus upon the child's pain experience (e.g., 'Are you seeing your friends this evening?'; 'I am wondering what we will have for dinner tonight.') and (3) Other, which included parent's inaudible utterances and statements about technical aspects of the pain task. The same procedure was used to assign mutually exclusive codes ('Pain talk', 'Non-pain talk' and 'Other') to child utterances. A primary coder assigned codes to all utterances. Reliability was assessed by having a second independent coder complete the same coding procedure for $25 \%$ of the transcripts and compute the intra-class correlations [3]. Reliability coefficients indicated good reliability (ranging from .71 to .91) for all coding categories. As we were primarily interested in the relative portion of parental pain-attending utterances, we calculated the proportion score of Parental pain-attending talk by dividing the number of parent utterances coded as pain attending talk by the total number of parent utterances. Similarly, a proportion score of Child pain talk (i.e., number of child utterances coded as pain talk divided by the total number of child utterances) was computed.

\subsection{Procedure}

All participants were invited by phone and received standardized information about the study. When parent and child provided verbal consent, they were invited to the laboratory at Ghent University. A letter confirming their appointment was sent to them. Upon arrival at the lab, one of two experimenters accompanied the parent and child to the test-room. 
Participants were told that we were interested in "how parents and children think and feel about the pain that children experience". The pain procedure was described, and the thermal heat stimulator was shown. After obtaining written parental consent and child assent, experimenter 1 stayed with the child in the test-room while experimenter 2 accompanied the parent to an adjacent room. During assessment of the child's pain tolerance level, parents completed a socio-demographic questionnaire and the PCS-P. Parents did not observe assessment of their child's heat tolerance level and were not informed that heat stimuli would be delivered at tolerance level. Parents then completed a dot-probe task [76] and the sensors for physiological recording were attached. When all the sensors were attached, parents (but not the children) received either neutral or threatening information concerning the pain task by means of a power-point presentation and completed the PCS-P state.

Parents were instructed to observe the pain and safety signals on the computer screen and their child's face on a television screen throughout the pain task. The television screen was positioned next to the computer screen on which the signals were presented. The child could not see the parent throughout the duration of the pain task. Parents were only provided video display of their child and therefore could not hear their child's utterances during the pain task. Providing auditory information to parents was not possible as the startle probes were presented to parents by means of a headphone. Moreover, this set-up is in line with previous research investigating parental responses to child pain using a similar experimental set-up [11,37]. Additionally, this set-up (of video display only) provides a pure measure of facial pain expression, which is not contaminated by child verbal pain behaviors. After the pain task, all sensors were removed and parents performed an additional computer task, which is beyond the scope of the current investigation [77]. After this task, parents and children were reunited in the test-room and were left alone for 3 minutes. During this 3-minute interval, parent-child interaction was videotaped. Parent and child were not informed about 
the video recording in order to capture spontaneous behaviors. After three minutes an experimenter returned to the test-room to fully debrief parents and children about the purpose of the study and additional written parental consent and child assent for the use of the video data was obtained.

\subsection{Data reduction and analysis}

By using Psychophysiological Analysis [PSPHA; 24] the magnitude of the eye blink modulation was calculated by subtracting the mean rectified baseline value $(0-20 \mathrm{~ms}$ after startle probe onset) from the rectified peak value in the $21-200 \mathrm{~ms}$ interval after probe onset. Trials with a baseline EMG-activity of at least $2.5 S D$ s above the mean baseline were visually inspected and rejected when regarded as a bad signal to noise ratio, or as "too-early" startle blink onset. The eye blink magnitude of the remaining trials was z-transformed across trials, within individuals. The impact of outliers was reduced by substituting z-scores smaller than 3 or greater than 3 by -3 or 3 , respectively [65].

To account for interference of the eye blink modulation, only trials in which no startle probe was present during the signal were used in analyses of corrugator EMG activity. The baseline value of corrugator EMG activity was defined as the mean corrugator EMG activity $1000 \mathrm{~ms}$ before the onset of the signal. In a second step, the baseline-corrected activity was calculated for every second of the $8000 \mathrm{~ms}$ during signals, with exception of the first second, in order to avoid interference from orientating reactions [26,60]. Finally, the baselinecorrected activity was averaged for safety and pain signals separately.

Statistical analyses were performed with SPSS statistical software, version 15.0. To investigate parental psychophysiological distress responses to their child's pain, a 2 (Signal: Pain vs. Safety) x 2 (Type of information: neutral vs. threatening information) mixed repeated measure ANOVA was performed on parents' corrugator EMG activity and eye blink modulation as the dependent variables. Child facial pain expression and parental catastrophic 
thought about their child's pain (PCS-P) were entered as covariates in all analyses. We calculated the effect-size Cohen's $d$ to quantify the difference between pain and safety signals, with $d=.20-.30$ indicating a small, $d=.50$ indicating a medium, and $d=.80$ indicating a large effect [17]. Moreover, partial eta squared $\left(\eta_{p}{ }^{2}\right)$ as calculated to have an estimation of the proportion of total variability attributable to a specific variable [with $\eta_{p}{ }^{2}=$ .01 indicating a small, $\eta_{p}{ }^{2}=.06$ indicating a medium, and $\eta_{p}{ }^{2}=.14$ indicating a large effect; $17,62]$.

A hierarchical linear regression was conducted to investigate the influence of parental catastrophic thought, threatening information and child facial pain expression on parental pain-attending talk. As previous studies have revealed a bidirectional relationship between child responses and parental behavior in response to child pain [see e.g., 5,6,16,80,83], we controlled for child pain talk when examining parental pain-attending talk. Child pain talk, Child facial pain expression, Type of information (neutral vs. threatening), and Parental catastrophic thought (PCS-P) were entered in the first step. In the second step, the two-way interactions between Type of information, Parental catastrophic thought and Child facial pain were entered. The variance-inflation factors were acceptable (range: $1.07-2.42$ ), suggesting that there was no problem of multicollinearity.

Statistically significant two-way interactions were investigated by plotting and testing the significance of the regression lines for high $(+1$ SD above the mean) and low (-1 SD below the mean) values of the moderator variable (i.e., Type of information or Child facial pain expression). For significant three-way interactions, similar regression lines were plotted separately for the two groups (i.e., neutral vs. threatening information) $[1,46]$. To reduce the effects of multicollinearity, continuous variables were centered [1].

\section{RESULTS}




\subsection{Descriptives and manipulation check}

Seven parent-child dyads were excluded from analyses due to technical problems with the equipment registering the psychophysiological measures $(N=4)$ or the video-recording equipment $(N=3)$. Therefore, final analyses were performed on 56 parent-child dyads. Power analysis indicated that this sample size was sufficient to detect a medium effect $(d=.50)$ with power .80 using $\alpha=.05$ two-tailed. Overall mean scores, standard deviations and correlations between all variables for the entire sample are shown in Table 1.

Children's mean tolerance level for the heat stimulus was $48.30^{\circ} \mathrm{C}\left(S D=2.36^{\circ} \mathrm{C}\right)$, and reported mean pain intensity at tolerance level was $7.09(S D=2.03)$. Parents' mean level of catastrophizing about their child's pain (PCS-P; $M=17.43, S D=8.12$ ) was comparable with previous research (e.g., [36] $(t(259)=.18, n s)$. Parental catastrophic thought about child pain showed a significant negative association with parental pain-attending talk $(r=-.32, p<.05)$. No significant associations between parental catastrophic thought and parental psychophysiological responses in anticipation of their child's pain were found.

To assess the effectiveness of our threat manipulation in parents (i.e., neutral versus threatening information), independent sample t-tests were performed on parental state catastrophic thought about their child's heat pain. Results indicated that the threat manipulation was effective. Specifically, in comparison to parents who received neutral information $(N=26)$, parents who received threatening information $(N=30)$ reported significantly higher state catastrophic thought concerning their child's pain both before $(M=$ $2.33 ; S D=1.76$ vs. $M=1.59 ; S D=.95)$ and $\operatorname{after}(M=1.46 ; S D=1.51$ vs. $M=.77, S D=.73)$ the pain task (both $t(54) \geq 2.00, p<.05$ ).

Insert Table 1 about here

\subsection{Parental psychophysiological responses during anticipation of child's pain}




\subsubsection{Parental corrugator EMG activity}

Analyses with corrugator EMG activity as dependent variable revealed no significant main or interaction effect of parental catastrophic thought (PCS-P) and child facial pain expression (all $F$ 's $<3.20, n s$ ). While a significant main effect of Signal was observed $(F(1,49)=4.92, p<.05, d=.55)$, the Signal $\mathrm{x}$ Type of information interaction also reached significance $(F(1,49)=4.80, p<.05)$. Independent sample t-tests showed that parents receiving threatening information $(M=.39 S D=.67)$ demonstrated more corrugator EMG activity during pain signals than parents receiving neutral information $(M=-.04, S D=.83$, $t(54)=2.15, p<.05, d=.57$; see Fig. 2). There was no significant difference between the two types of information provided to parents for corrugator activity during safety signals $\left(M_{\text {(low threat })}=.01, S D=.88 ; M_{\text {(high threat })}=-.21, S D=.67 ; t(54)=1.05, n s\right)$. Additional paired sample t-tests, performed for each group separately, revealed that the difference in corrugator EMG activity during pain vs. safety signals was only significant for parents who received threatening information $(t=3.18, p<.01)$. In contrast, no difference in corrugator EMG activity during pain vs. safety signals was found for parents who received neutral information $(t=-.22, n s)$. This suggests that, for corrugator EMG activity, the effect of signal was dependent upon type of information provided to parents prior to the pain task, with parents receiving threatening information showing more corrugator EMG activity during pain signals than during safety signal in comparison to parents who received neutral information (see Figure 2).

Insert Fig 2 about here

\subsubsection{Parental eye blink modulation}

Similar analyses were performed with parental eye blink modulation (indexing parental fear-potentiated startle) as dependent variable. The Signal $\mathrm{x}$ Type of information $\mathrm{x}$ Child's facial pain expression interaction reached significance $\left(F(1,49)=8.84, p<.01, \eta_{p}{ }^{2}=\right.$ .15). No other significant main or interaction effects were observed (all $F<2.98, n s$ ). 
Following up on the interaction effect, analyses for each group separately revealed that the interaction between Signal and Child facial pain expression during actual pain induction was only significant for the parents receiving threatening information $(F(1,28)=7.58, p<.05)$. To illustrate the pattern, we analyzed the regression lines of children showing low vs. high facial pain expression for parents who received threatening information. Significance tests indicated that, in the case of high child facial expression, parents provided with threatening information showed augmented eye blink modulation (i.e., fear-potentiated startle) during pain signals compared with safety signals $(F(1,28)=5.57, p<.05$; for the purpose of clarity, Fig. 3 depicts a bar chart containing the mean values of parental eye blink modulation for high and low child facial pain expression). As apparent in Figure 3, parental eye blink modulation was unaffected by threatening information when children expressed low pain $(F(1,28)=2.71$, ns).

Insert Fig 3 about here

3.3 Parental pain-attending talk in response to their child's pain

In the analysis with parental pain-attending talk as the dependent variable, no significant main effect or interactions with child's facial pain expression were found (all $\beta<$ $|.20|, n s)$. Although parental catastrophic thought showed a main effect upon parental painattending talk $(\beta=-.38, t=-3.39, p<.01)$, the interaction between parental catastrophizing (PCS-P) and the Type of information also reached significance $(\beta=.29, t=2.67, p<.05)$. This indicated that the influence of parental catastrophizing was conditional upon the information provided to parents prior to the pain task. To illustrate this pattern, we plotted separate regression lines for the parents who received neutral information and the parents who received threatening information (see Fig. 4). The slope for the parents who received threatening information did not reach significance $(\beta=.01, n s)$; parents provided with threatening information engaged in equal levels of pain talk independently of their level of catastrophic thought about their child's pain. In contrast, the slope for the parents who 
received neutral information was significant $(\beta=-.42, \mathrm{p}<.001)$, indicating that high catastrophizing parents talked significantly less about their child's pain than low catastrophizing parents when parents received neutral information. However, in line with our expectations, additional between-group analyses indicated that high, but not low catastrophizing parents, were sensitive to threatening information; i.e. high catastrophizing parents receiving threatening information talked significantly more about their child's pain than high catastrophizing parents receiving neutral information $(\beta=.28, p<.01$; see Figure 4). No such difference was found for low catastrophizing parents $(\beta=-.07, n s)$. Finally, child pain talk showed a significant main effect on parental pain-attending talk $(\beta=.80, t=10.86, p$ $<.001$ ), indicating that parents engaged in more pain talk if their child talked more about their pain.

\section{DISCUSSION}

The present study examined the influence of parental catastrophic thought about child pain on parental experience of distress in anticipation of child pain and behavioral responses following pain induction. The moderating influence of contextual threat (threatening information and child pain expression) was also investigated. Schoolchildren performed a pain task while observed by one of their parents. During the pain task, trials were preceded by a blue or yellow circle, signaling possible pain stimulation (pain signal) or no pain stimulation (safety signal). Prior to the pain task, parents received either neutral or threatening information regarding the pain stimulus. Parental distress was measured by psychophysiological indices. Parental "pain-attending behavior" was assessed during a 3minute interaction between parent and child after the pain task. We expected that higher levels of parental catastrophizing, threatening information, and child pain expression would be associated with elevated levels of parental distress and pain-attending talk. Additionally, 
we expected that the influence of parental catastrophizing would be enhanced in a threatening context due to threatening information and/or child pain expression.

The results can be summarized as follows. In terms of parental distress, parents who received threatening about the pain task showed more corrugator EMG activity when anticipating pain in their child than parents receiving neutral information. Moreover, greater corrugator EMG activity in response to pain vs. safety signals was only apparent for parents receiving threatening information. Similarly, parents receiving threatening information showed a heightened fear-potentiated startle during pain signals compared to safety signals, but only if their child showed high pain expression. No significant impact of parental catastrophizing upon parental psychophysiological distress responses was observed. In contrast, parental catastrophizing significantly impacted parental behavior when contextual threat was high. Specifically, high catastrophizing parents engaged in more pain-attending talk when provided with threatening rather than neutral information regarding the child's pain experience. Moreover, when contextual threat was low (i.e., when receiving neutral information) high catastrophizing parents talked significantly less about child pain compared with low catastrophizing parents.

The current findings corroborate and extend previous self-report literature regarding parental distress $[11,37,39,68]$ by using psychophysiological indices of parental emotional reactions. Generally, the results indicate that parents experience automatic aversive emotional reactions in response to observing their child in pain and support the importance of contextual threat in parental reactions. In terms of parental distress, the present findings suggest that contextual threat may play a more important role than the overall tendency of parents to endorse catastrophic thought about child pain. At first sight, these findings stand in contrast with prior research highlighting pain catastrophizing as an important construct in understanding parental responses [36,39]. However, our findings corroborate recent evidence 
showing that the specific level of threat persons attach to a situation has higher predictive value in explaining their response to pain than their general tendency to interpret pain as threatening (i.e., catastrophizing) [11,12]. Future research is needed to shed more light upon the relative importance of parental trait versus state catastrophic thought in explaining parental responses to child pain.

In terms of contemporary theories of empathy [35], our findings demonstrate the individual and combined impact of contextual variables on parental emotional responses in anticipation of child pain. Specifically, threatening information was "sufficient" to induce a general aversive state/expression in parents, as evidenced by heightened corrugator EMG activity. However, heightened fear-potentiated startle was observed only in the context of both threatening information and high child pain expression. The latter observation is in line with findings that the level of corrugator EMG activity is primarily influenced by the aversive content of the situation, while the arousal level of the situation affects the potentiation of the fear-potentiated startle. Therefore, in the absence of additional arousing features (such as heightened child pain expression) threatening information may not create a sufficiently arousing situation to produce elevated fear-potentiated startle $[8,22]$. Furthermore, evidence suggesting that the two psychophysiological indices may tap into slightly different aspects of emotional responses may account for differential findings in the present study. Specifically, the fear-potentiated startle may reflect a sympathetic defensive-motivational reflex in parents, while the corrugator EMG activity primarily assesses parental facial activity when processing the negative circumstance of anticipating pain in their child $[8,40]$. As psychophysiological measurement is a relatively new methodology to investigate parental emotional responses to child pain, further research is needed.

Heightened contextual threat, in combination with parental catastrophic thought, also significantly influenced parental "pain-attending behavior". Specifically, high catastrophizing 
parents attended more to the pain situation during interaction with their child (i.e., engaged in more pain-attending talk) when provided with threatening as opposed to neutral information. However, in the context of low contextual threat, high catastrophizing parents engaged in less pain-attending talk than did low catastrophizing parents. In contrast, low catastrophizing parents engaged in comparable pain-attending behavior regardless of the information provided. The differential impact of contextual threat for high vs. low catastrophizing parents is consistent with an affective-motivational account of pain, conceptualizing pain as a source of distress, both drawing attention and associated with an urge to escape [2,28,72], particularly when perceived as highly threatening $[54,74]$. In the interpersonal context, painattending talk can be seen as a behavioral indicator of attention capture by pain, or reflect behavioral efforts at distress modulation caused by someone else's pain experience. Accordingly, it is possible that, in the context of low threat, high catastrophizing parents' lessened pain-attending talk reflects an avoidance response (i.e., avoiding information regarding the child's pain experience). However, in the context of high threat, high catastrophizing parents' increased pain-attending talk may reflect either greater attention toward pain or failure of avoidance strategy. In contrast, low catastrophizing parents may be better able to regulate distress associated with child pain, thus attenuating induced threat [34]. Related to this finding, the results obtained with the dot-probe paradigm in a preceding part of the study indicated that only low catastrophizing parents selectively attended to faces expressing low facial expression, while higher catastrophizing parents increasingly attended away from low pain faces [76]. It is possible that the avoidance tendencies of parents with heightened catastrophic thought may conflict with or be compromised by increased difficulty disengaging from pain in highly threatening or distressing situations $[15,21,38,71]$.

The above findings have clear clinical implications as they suggest that the type of information provided to parents about anticipated child pain (e.g., by a physician prior to a 
painful procedure) could influence parental emotional and behavioral response to child pain. However, more research is needed to disentangle the relative impact of various contextual variables, such as pain expression, contextual information and the parent-child relationship, upon parental pain-attending responses [42]. Additionally, further research is needed to investigate how heightened parental distress may influence a range of parental behaviors, and in turn impacts child functioning in distinct clinical contexts. For example, in the context of acute child pain, giving attention to the pain and searching for a cause and related solution may be an adaptive response fostering pain relief. However, in the context of chronic pain, disengaging from unattainable pain-relief goals in order to engage in other attainable lifegoals despite the pain is associated with better well-being [29,57,58,59]. Parental level of distress in response to child pain and how parents manage such distress may be important in understanding why parents keep focusing on reducing child pain despite several failed attempts [29]. Although further research is needed, it is possible that parents who can attenuate the contextual threat and associated distress may be able to adapt their behavior in accordance with the needs of their child instead of having the urge to avoid or diminish the pain in order to reduce their feelings of distress $[4,30,38]$.

A number of limitations need to be considered, each pointing to new directions for research. First, because the sample size was rather small, only medium to large effects could be detected. Second, the sample consisted of schoolchildren and their parents participating in a pain task within a safe experimental environment. Further research is needed to establish if similar pattern of results can be found in real-life situations and in parents of children with chronic or recurrent pain. Third, although parental state catastrophic thought increased due to experimental threat manipulation, the manipulation did not provoke high levels of catastrophizing or distress. Moreover, the heat stimuli provoked rather low levels of child facial pain display. Generalization of the results may therefore be limited. Fourth, the 
majority of participating parents were mothers. As mothers' responses may differ from those of fathers $[39,50,61,78]$, future studies are needed to investigate whether similar patterns are true for fathers. Fifth, the coding system we used was limited to verbal behavior. Non-verbal behavior, however, is also an important feature of parent-child communication [42,82]. Therefore, future research could benefit from investigating if the same findings account for non-verbal parental behavior.

Despite these limitations, the results add to our understanding of child pain within a social context by showing that parental catastrophizing thoughts about child pain, as well as contextual threat-inducing variables, have an impact upon parental emotional and behavioral reactions to child pain.

\section{Acknowledgments}

The authors would like to thank Tineke Bettens en Noortje Verleyen for their help with the data collection and data-input. The study was supported by a Pain Research EFIC Grünenthal Grant Prize and an IASP Early Career Research Grant, awarded to Tine Vervoort. There are no conflicts of interest that may arise as a result of the research presented in this article. 


\section{REFERENCES}

[1] Aiken LS, West SG. Multiple regression: testing and interpreting interactions. Newbury Park, CA: Sage, 1991.

[2] Auvray M, Myin E, Spence C: The sensory-discriminative and affective-motivational aspects of pain. Neurosci Biobehav R 2010;34:214-223.

[3] Bakeman R. Behavioral observation and coding. In: Reis HT, Judd CM, editors. Handbook of research methods in social and personality psychology. New York: Cambridge University Press; 2000.

[4] Batson CD, Fultz J, Schoenrade PA. Distress and empathy: two quantitatively distinct vicarious emotions with different motivational consequences. J Pers 1987;55:19-39.

[5] Blount RL, Corbin SM, Sturges JW, Wolfe VV, Prater, JM, James, LD. The relationship between adult's behaviour and child coping and distress during BMA LP procedures: a sequential analysis. Behav Ther1989;20:585-601.

[6] Blount RL, Landolf-Fritsche B, Powers SW, Sturges, JW. Differences between high and low coping children and between parent and staff behaviors during painful medical procedures. J Pediatr Psychol 1991;16:795-809.

[7] Blumenthal TD, Cuthbert BN, Filion DL, Hackley S, Lipp OV, Van Boxtel A. Committee report: Guidelines for human startle eyeblink electromyographic studies. Psychophysiol $2005 ; 42: 1-15$.

[8] Bradley MM, Codispoti M, Cuthbert BN, Lang PJ. Emotion and motivation I: defensive and appetitive reactions in picture processing. Emotion 2001;1:276-298.

[9] Bradley MM, Silakowski T, Lang PJ. Fear of pain and defensive activation. Pain 2008;137:156-163. 
[10] Breau LM, McGrath PJ, Craig KD, Santor D, Cassidy KL, Reid GJ. Facial expression of children receiving immunizations: a principal components analysis of the child facial coding system. Clin J Pain 2001;17:178-86.

[11] Caes L, Vervoort T, Eccleston C, Vandenhende M, Goubert L. Parental catastrophizing about child's pain and its relationship with activity restriction: The mediating role of parental distress. Pain 2010;152:212-222.

[12] Campbell CM, Kronfli T, Buenaver LF, Smith MT, Berna C, Haythornthwaite JA, Edwards RR. Situational versus dispositional measurement of catastrophizing: associations with pain responses in multiple samples. J of Pain 2010;11:443-453.

[13] Chambers CT. The role of family factors in pediatric pain. In: McGrath PJ, Finley GA, editors. Context of pediatric pain: biology, family, culture. Seattle: IASP Press; 2003. p. 99130

[14] Chambers CT, McGrath PJ, Gilbert CA, Craig KD. Child Facial Coding System revised manual. Halifax, NS: IWK-Grace Health Centre, Dalhousie University \& University of British Columbia; 1996.

[15] Cisler, JM, Koster EHW. Mechanisms of attentional biases toward threat in anxiety disorders: An integrative review. Clin Psychol Rev 2010;30:203-216.

[16] Claar RL, Simons LE, Logan DE. Parental response to children's pain: the moderating impact of children's emotional distress on symptoms and disability. Pain 2008;138:172-179.

[17] Cohen J. Statistical power analysis for the behavioural sciences. CA, San Diego: McGraw- Hill; 1988.

[18] Cohen LL, Manimala R, Blount RL. Easier said than done: what parents say they do and what they do during children's immunizations. Child Health Care 2000;29:79-86. 
[19] Crombez G, Bijttebier P, Eccleston C, Mascagnic T, Mertens G, Goubert L, Verstraeten $\mathrm{K}$. The child version of the pain catastrophizing scale (PCS-C): a preliminary validation. Pain 2003;104:639-646.

[20] Crombez G, Eccleston C, Baeyens F, Eelen P. When somatic information threatens, catastrophic thinking enhances attentional interference. Pain 1998;75:187-198.

[21] Crombez G, Eccleston C, Baeyens F, Eelen P. Attentional distruption is enhanced by the threat of pain. Beh Res Ther 1998;36:195-204.

[22] Cuthbert BN, Bradley MM, Lang PJ. Probing picture perception: activation and emotion. Psychophysiol 1996;33:103-111.

[23] Davis M, Falls WA, Campeau S, Kim M. Fear-potentiated startle: a neural and pharmacological analysis. Behav Brain Res 1993;58:175-98.

[24] De Clercq A, Verschuere B, De Vlieger P, Crombez G. Psychophysiological Analysis (PSPHA): a modular script-based program for analyzing psychophysiological data. Behav Res Methods 2006;38:504-510.

[25] Dimberg U. Facial reactions to emotional stimuli: evidence for 'facial affect' programs. Int J Psychophysiol 2000;35:31-31.

[26] Dimberg U, Karlsson B. Facial reactions to different emotionally relevant stimuli. Scand J Psychol 1997;38:297-303.

[27] Dix T, Gershoff ET, Meunier LN, Miller PC. The affective structure of supportive parenting: depressive symptoms, immediate emotions, and child-oriented motivation. Dev Psychol 2004;40:1212-1227.

[28] Eccleston C, Crombez G: Pain demands attention: a cognitive-affective model of the interruptive function of pain. Psychol Bull 1999;125:356-366.

[29] Eccleston C, Crombez G. Worry and chronic pain: a misdirected problem solving model. Pain 2007;132:233-236. 
[30] Eisenberg N, Fabes RA, Murphy B, Karbon M, Maszk P, Smith M, O’Boyle C, Suh K. The relations of emotionality and regulation to dispositional and situational empathy-related responding. J Pers Soc Psychol 1994;66:776-797.

[31] Ekman P, Friesen W. Investigator's guide to the Facial Action Coding System. Palo Alto, CA: Consulting Psychologists Press: 1978.

[32] Fridlund AJ, Cacioppo JT. Guidelines for human electromyographic research. Psychophysiol 1986;23:567-589.

[33] Gilbert CA, Lilley CM, Craig KD, McGrath PJ, Court CA, Bennett SM, Montgomery CJ. Postoperative pain expression in preschool children: validation of the child facial coding system. Clin J Pain 1999;15:192-200.

[34] Goubert L, Craig KD, Buysse A. Perceiving others in pain: experimental and clinical evidence on the role of empathy. In Ickes W, Decety J, editors. The Social Neuroscience of Empathy. Massachusetts: The MIT Press, 2009. pp.153-165.

[35] Goubert L, Craig KD, Vervoort T, Morley S, Sullivan MJL, Williams AC de C, Cano A, Crombez C. Facing others in pain: the effects of empathy. Pain 2005;118:285-288.

[36] Goubert L, Eccleston C, Vervoort T, Jordan A, Crombez G. Parental catastrophizing about their child's pain: the parent version of the Pain Catastrophizing Scale. Pain 2006;123:254-263.

[37] Goubert L, Vervoort T, Cano A, Crombez G. Catastrophizing about their children's pain is related to higher parent-child congruency in pain ratings: an experimental investigation. Eur J Pain 2009;13:196-209.

[38] Goubert L, Vervoort T, Crombez G. Pain demands attention from others: the approach/avoidance paradox. Pain 2009;143:5-6. 
[39] Goubert L, Vervoort T, Sullivan MJL, Verhoeven K. Parental emotional responses to their child's pain: the role of dispositional empathy and catastrophizing about their child's pain. J Pain 2008;3:227-279.

[40] Grillon C, Baas J. A review of the modulation of the startle reflex by affective states and its application in psychiatry. Clin Neurophysiol 2003;114:1557-1579.

[41] Grillon C, Ameli R, Wood SW, Merikangas SK, Davis M: Fear-potentiated startle in humans: effects of anticipatory anxiety on the acoustic blink reflex. Psychopysiol $1991 ; 28: 588-595$.

[42] Hadjistravropoulos T, Craig KD, Duck S, Cano A, Goubert L, Jackson PL, Mogil JS, Rainville P, Sullivan M, Williams AC, Vervoort T, Fitzegerald TD. A biopsychosocial formulation of pain communication. Psychol Bull, in press.

[43] Hamm AO, Greenwald MK, Bradley MM, Lang PJ. Emotional learning, hedonic change, and the startle probe. J Abnormal Psychol 1993;102:453-465.

[44] Hermann C, Hohmeister J, Demirakça S, Zohsel K, Flor R. Long-term alteration of pain sensitivity in school-aged children with early pain experiences. Pain 2006;125:278-285.

[45] Herzog T. Research methods in the social sciences. Harper Collins College Publishers; 1996.

[46] Holmbeck GN. Post-hoc probing of significant moderational and mediational effects in studies of pediatric populations. J Pediatr Psychol 2002;27:87-96.

[47] Inquisit (Version 2.0.61004.5). Computer program. Seattle, WA: Millisecond Software, 2006.

[48] Janssens KAM, Oldehinkel AJ, Rosmalen JGM. Parental overprotection predicts development of functional somatic symptoms in young adolescents. J Pediatr 2009;154:918923. 
[49] Jordan A, Eccleston C, McCracken LM, Connell H, Clinch J. The Bath Adolescent Pain

- Parental Impact Questionnaire (BAP-PIQ): development and preliminary psychometric evaluation of an instrument to assess the impact of parenting an adolescent with chronic pain. Pain 2008;137:478-487.

[50] Lamb ME, Tamis-Lemonda CS. The role of the father: an introduction. In Lamb ME, editor. The role of the father. Fourth edition. Hoboken, New Jersey: John Wiley \& Sons; 2004.

[51] Lang PJ, Bradley MM, Cuthbert BN: Emotion, attention, and the startle reflex. Psychol Rev 1990;97:377-39.

[52] Lang PJ, Bradley MM, Cuthbert BN: A motivational analysis of emotion: reflex-cortex connections. Psychol Sci 1992;3:44-49.

[53] Lanzetta JT, Englis BG. Expectations of cooperation and competition and their effects on observers' vicarious emotional responses. J Pers Soc Psychol 1989;56:543-554.

[54] Leeuw M, Goossens MEJB, Linton SJ, Crombez G, Boersma K, Vlaeyen J. The fearavoidance model of musculoskeletal pain: current state of scientific evidence. J Behav Med 2006; 30:77-94.

[55] Leventhal H, Brown D, Shacham S, Engquist G. Effects of preparatory information about sensations, threat of pain, and attention on cold pressor distress. J Pers Soc Psychol 1979;37:688-714.

[56] Logan DE, Scharff L. Relationships between family and parent characteristics and functional abilities in children with recurrent pain syndromes: an investigation of moderating effects on the pathway from pain to disability. J Pediatr Psychol 2005;30:698-707.

[57] Massey EK, Garnefski N, Gebhardt WA. Goal frustration, coping and well-being in the context of adolescent headache: a self-regulation approach. Eur J Pain 2009;13:977-984. 
[58] McCracken L, Gauntlett-Gilbert J, Eccleston C. Acceptance of pain in adolescents with chronic pain: validation of an adapted assessment instrument and preliminary correlation analyses. Eur J Pain 2009;14:316-320.

[59] McCracken LM, Vowles KE, Eccleston E. Acceptance of chronic pain: component analysis and a revised assessment method. Pain 2004;107:159-166.

[60] McIntosh DN, Reichmann-Decker A, Winkielman P,Wilbarger JL. When the social mirror breaks: deficits in automatic, but not voluntary, mimicry of emotional facial expressions in autism. Developmental Sci 2006;9:295-302.

[61] Moon, EC. Chambers CT, McGrath PJ. "He Says, She Says"': a comparison of fathers' and mothers' verbal behavior during child cold pressor pain. J Pain, in press.

[62] Olejnik S, Algina J: Measures of effect size for comparative studies: applications, interpretations, and limitations. Contemp Educ Psychol 25:241-286,2000.

[63] Palermo TM, Chambers CT. Parent and family factors in pediatric chronic pain and disability: an integrative approach. Pain 2005;119:1-4

[64] Palermo TM, Eccleston E. Parents of children and adolescents with chronic pain. Pain 2009;146:15-17.

[65] Patrick CJ, Bradley MM, Lang PJ. Emotion in the criminal psychopath: startle reflex modulation. J Abnorm Psychol 1993;102:82-92.

[66] Perquin CW, Hazebroek-Kampschreur AAJM, Hunfeld JAM, Bohnen AM, van Suijlekom-Smit LWA, Passchier J, van der Wouden JC.Pain in children and adolescents: a common experience. Pain 2000;87:51-58.

[67] Preston SD, de Waal FBM. Empathy: its ultimate and proximate bases. Behav Brain Sci 2002;25:1-72. 
[68] Sieberg CB, Williams S, Simons L. Do parent protective responses mediate the relation between parent distress and child functional disability among children with chronic pain? J Pediatr Psychol 2011, 36:1043-1051.

[69] Sullivan MJL, Bishop SR, Pivik J. The pain catastrophizing scale: development and validation. Psychol Assessment 1995;7: 524-532.

[70] Sweet SD, McGrath PJ. Relative importance of mothers' versus medical staffs' behavior in the prediction of infant immunization pain behavior. J Pediatr Psychol 1998;23:249-256.

[71] Van Damme S, Crombez C, Eccleston C. Disengagement from pain: the role of catastrophic thinking about pain. Pain 2004;107:70-76.

[72] Van Damme S, Legrain V, Vogt V, Crombez G: Keeping pain in mind: a motivational account of attention to pain. Neurosci Biobehav R 2010;34: 204-213.

[73] Vaughan KB, Lanzetta JT: Vicarious instigation and conditioning of facial expressive and autonomic responses to a model's expressive display of pain. J Pers Soc Psychol 1980;38:909-923.

[74] Vlaeyen JWS, Linton S. Fear-avoidance and its consequences in chronic musculoskeletal pain: a state of the art. Pain 2000;85:317-332.

[75] Vlaeyen JWS, Timmermans C, Rodriguez LM, Crombez G, van Horne W, Ayers GM, Albert A, Wellens HJJ. Catastrophic thinking about pain increases discomfort during internal atrial cardioversion. J Psychosom Res 2004;56:139-144.

[76] Vervoort T, Caes L, Crombez G, Koster EHW, Van Damme S, Dewitte M, Goubert L. Parental catastrophizing about child's pain and selective attention to varying levels of facial pain expression in children: a dot-probe study. Pain 2011;152:1751-1757.

[77] Vervoort T, Caes L, Trost Z, Goubert L. Parental attention to their child's pain is modulated by threat-value of pain. submitted. 
[78] Vervoort T, Huguet A, Verhoeven K, Goubert L. Mothers' and fathers' responses to their child's pain moderate the relationship between the child's pain catastrophizing and disability. Pain 2011,152:786-793.

[79] Vowles KE, Cohen LL, McCracken LM, Eccleston C. Disentangling the complex relations among caregiver and adolescent responses to adolescent chronic pain. Pain 2010;151:680-686.

[80] Walker LS, Claar RL, Garber J. Social consequences of children's pain: when do they encourage symptom maintenance? J Pediatr Psychol 2002;27:689-698.

[81] Walker LS, Williams SE, Smith GA, Garber J, Van Slyke DA, Lipani TA. Parent attention versus distraction: impact on symptom complaints by children with and without chronic functional abdominal pain. Pain 2006;122:43-52.

[82] Williams ACC. Facial expression of pain: an evolutionary account. Behav Brain Sci $2002 ; 25: 439-48$.

[83] Williams SE, Blount RL, Walker LS. Pain threat appraisal and catastrophizing moderate the impact of parent verbal behavior on children's symptom complaints. J Pediatr Psychol 2011;36:55-63.

[84] Zohsel K, Hohmeister J, Flor H, \& Hermann C. Somatic pain sensitivity in children with recurrent abdominal pain. Am J Gastroenterol 2008;103:1517-1523. 


\section{Figure Legend}

Figure 1. Schematic overview of one trial.

Figure 2. The influence of Signal and threatening contextual information on parental corrugator EMG activity. ${ }^{*} p<.05 ; * * p<.01$

Figure 3. The influence of Signal and Child facial pain expression on parental fear-potentiated startle for parents assigned to the high threat group. ${ }^{*} p<.05 ; * * p<.01$

Figure 4. The moderation of threatening contextual information upon the relation between parental catastrophic thought (PCS-P) and parental pain-attending talk. ${ }^{*} p<.05 ; * * p<.01$ 
Table 1

Table 1

Overall means (M), standard deviations (SD) and Pearson correlation coefficient for all parents $(N=56)$

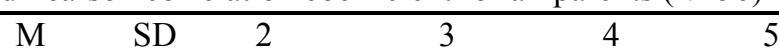

\begin{tabular}{|c|c|c|c|c|c|c|c|c|c|c|}
\hline 1. & PCS-P & 17.43 & 8.12 & .08 & -.08 & .01 & .19 & $-.32 *$ & -.10 & -.23 \\
\hline 2. & Corrugator EMG during safety signals & -.11 & .77 & & -.04 & -.06 & $-.31 *$ & -.08 & -.04 & -.02 \\
\hline 3. & Corrugator EMG during pain signals & .19 & .77 & & -- & -.09 & .23 & .18 & .02 & .18 \\
\hline 4. & Eye blink modulation during safety signals & -.05 & .16 & & & -- & -.14 & .19 & -.14 & .25 \\
\hline 5 . & Eye blink modulation during pain signals & -.04 & .17 & & & & -- & -.18 & .08 & -.19 \\
\hline 6. & Parental pain-attending talk & .56 & .22 & & & & & - & -.09 & $.82 * *$ \\
\hline 7. & Child's facial pain expression & 7.74 & 4.88 & & & & & & - & -.00 \\
\hline 8. & Child's pain talk & .58 & 21 & & & & & & & - \\
\hline
\end{tabular}

$* \mathrm{p}<.05 ; * * \mathrm{p}<.001 ;$ PCS-P = Pain Catastrophizing Scale for Parents, EMG = Electromyografie 
Figure 1

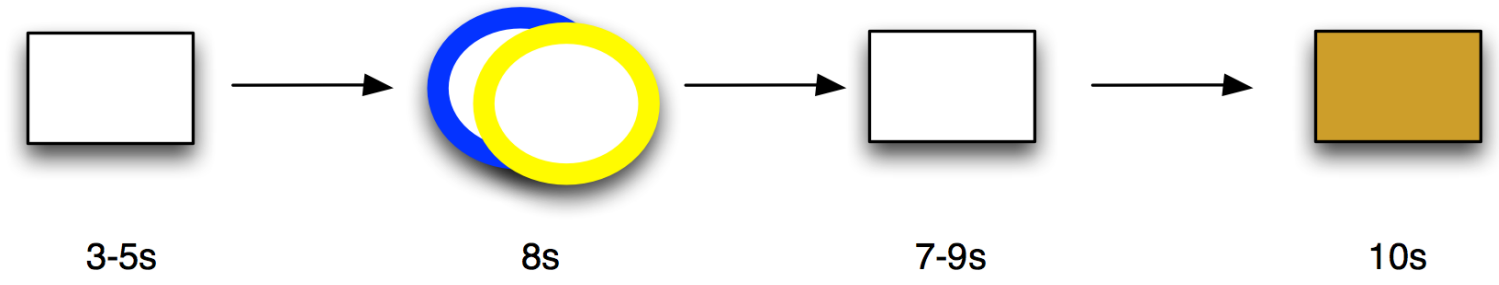


Figure 2

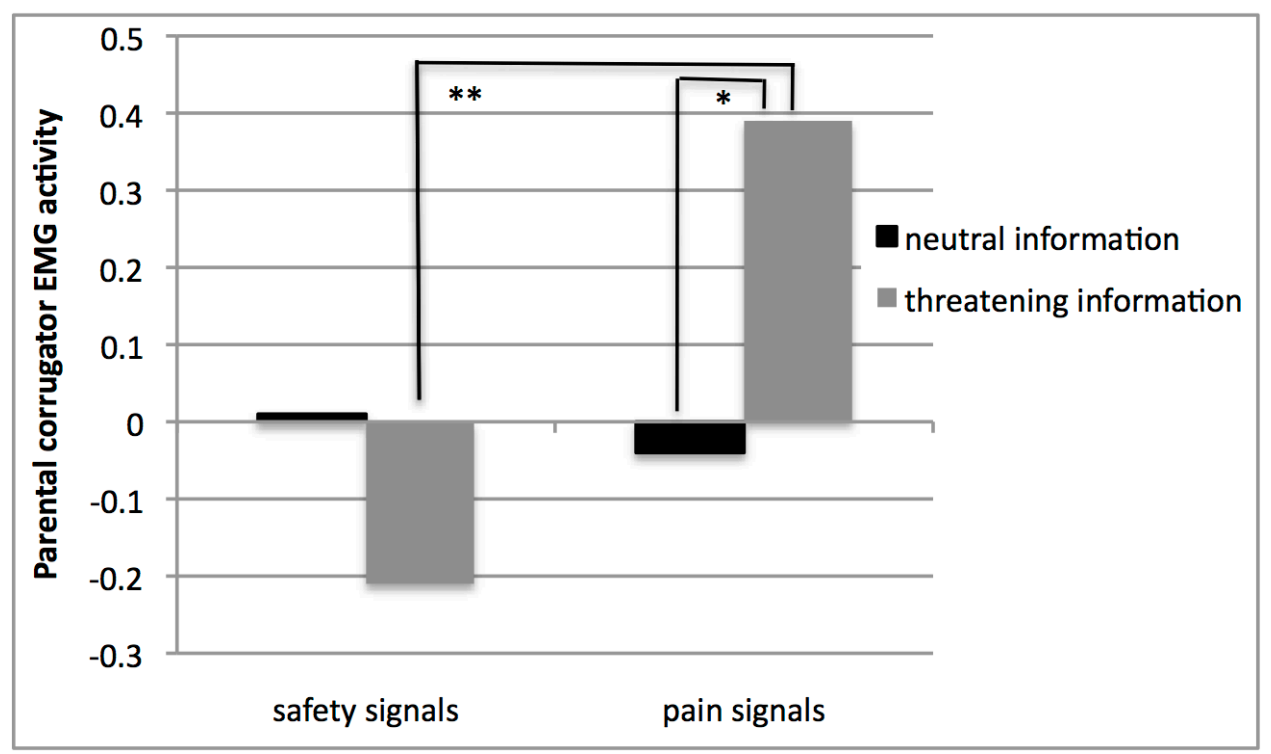


Figure 3

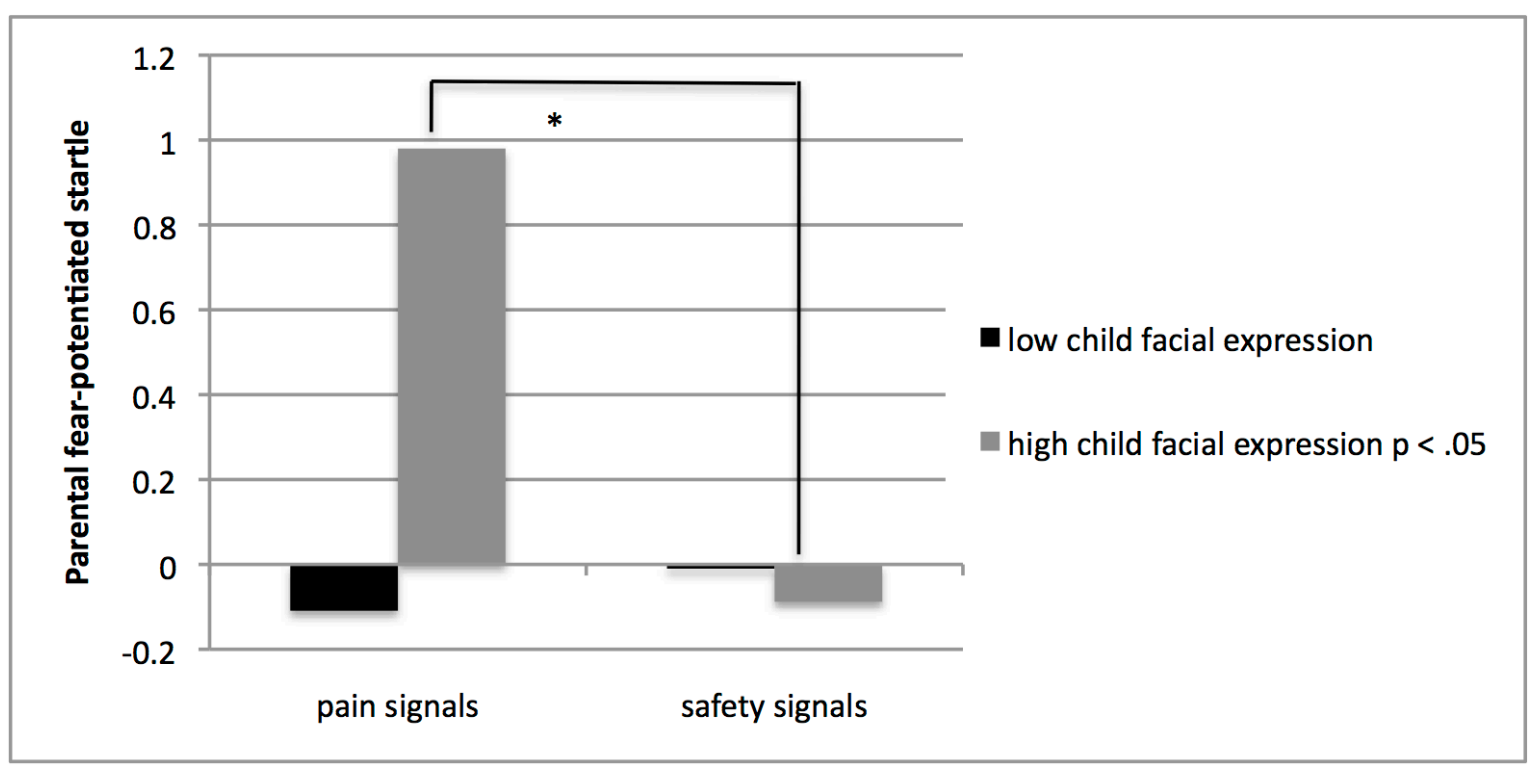


Figure 4

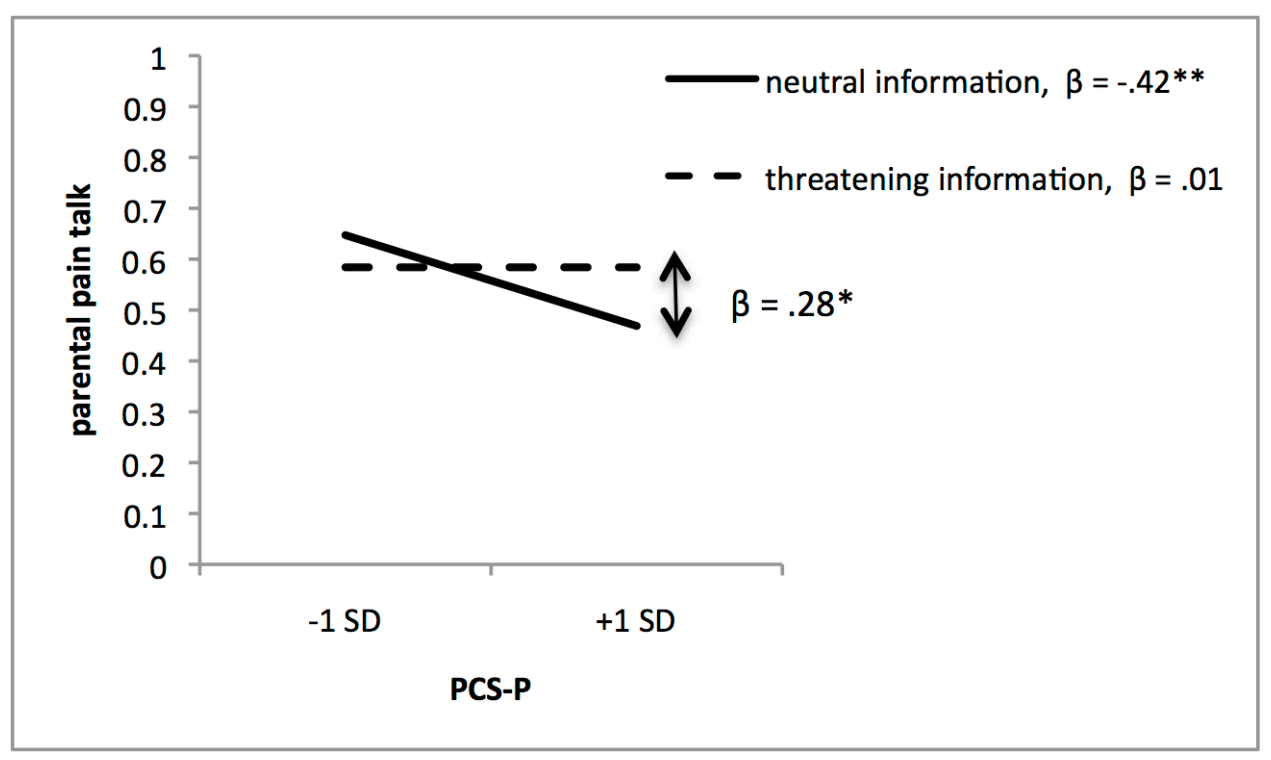

